\title{
Analysis on Training of Practical Ability in the Major of Information Management and Information System Based on Local University
}

\author{
Jianbiao Huang, Jiaming Zhong and Li Jiang* \\ Xiangnan University, Chenzhou, China, 42300 \\ *The corresponding author
}

Keywords: Local university; Information management; Information system; Practical ability

\begin{abstract}
Local universities must to adapt local economic and social development, and generally located at the applied technology universities. The major of information management and information system is a highly practical interdisciplinary major, this paper analyzes the construction of practical ability and major problems, at last, it puts forward some methods for promotion the practical ability to students in our Local application-oriented university, and to promote construction of the characteristic major.
\end{abstract}

\section{Practice Ability System and Classification of the Information Management Major}

The local applied university is a kind of form which is between the research university and the higher vocational college, is the revision to the traditional higher education training mode, and is the extension of the concept of higher vocational education. The function of local Applied Technology University is mainly manifested in three aspects: one is application of technology talents training, the second is focused on applied research and development projects of scientific research, and the third is for local services to local economic and social development.

Information management and information system (hereinafter referred to as " information management major") is that in 1998, Ministry of Education promulgated "Catalogue of the undergraduate course in Colleges and Universities", from the original science and technology information, information science, economic information management, management information systems and forestry information management, the 5 professional integrated into the new professional, in 1999 the formal enrollment. Through the way of the integration to make a number of coverage which is too narrow merge into a wide range of professional coverage, it is one of the important reform measures in China's information construction in the field of education, has far-reaching significance for the cultivation of the information construction in our country needing "wide caliber, thick foundation, high quality" talent. After many years construction, the specialty has trained a large number of talents for information construction in our country who are good at both the information technology and the management. According to statistics, currently, information management major has been opened in more than 600 universities, become one of the biggest professionals, but the quality of the students and the actual needs of enterprises still exist a certain gap. The main reason is that a lot of university personnel training is still based on the theory of teaching, there being a certain gap between the enterprise application needs. Therefore, in the training of professional talents, it requires that students can accept systematic practical training in the school period, improve the level of practical ability of graduates.

In recent years, the research of information system is mainly reflected in the two dimensions of behavior and technology. Behavior dimension is concerned with the "use", namely the use of information technology and information system; technology dimension is concerned with the "making", namely information system information is that how to express and deal with, knowledge is how to discover, the system is how to construct. So the practice ability of the major is mainly in the "use" and "building" two dimensions. After my school years fuse professional education exploration and synthesis of other research results, summed up the information management 
profession practical ability can be divided into three types.

Basic Skills. The part skills are not unique for information management and most of the subjects will strengthen the cultivation of this ability which to information management profession is very important. Because if there is no these basic knowledge and skills for information management graduates, they could not have a high level of the ability of information system. This part of skills mainly refers to the leadership ability and cooperation ability, communication ability, negotiation ability, analysis and thinking ability, mathematical ability, English ability, innovation and adaptation ability, etc.

Specialty of Information Management. Include the main computer and network basic skills, enterprise informatization solution design and improvement skill, information systems analysis, design, development and implementation skills, skills of informatization project management, information management skills, and information processing skills.

Related Domain Skills. This is as important as the first two skills, but there are differences, because the knowledge and skills related to the field will change with the different areas of the field. Generally related and most common areas with information management are business, but there are also a lot of other areas, such as accounting or finance, government, health care, non-governmental organizations and so on. Although key courses in different areas may be different, many professions agree that financial, accounting, marketing and management is a key course in the field of business.

\section{The Main Problems of the Practice Ability Training of Information Management}

Laboratory and Practice Base Construction Does not Meet the Requirements of Professional Development. Information management major relative to other management majors needs higher requirements to practical teaching conditions. There are more experiment course and practice projects, such as electronic business, ERP, simulation sand table, network equipment, etc., also need to the construction of internal and external comprehensive training base. Due to funding and other reasons, it is difficult to meet the professional requirements of the experimental conditions. Practice base construction is directly related to the quality of practical teaching, and has a very important role in the practice of ability training. In addition, the students who participated in the internship are still in the learning stage, are difficult to fully qualified for the actual information management of enterprises. And now a lot of enterprises being private enterprises, they did not have the obligation to accept internships and do not want to receive, Even receiving, it will not allow students to contact their core departments and important management issues, so the practice base is not only difficult to build, but also the use is poor.

Schools Lack of Incentives. Although many colleges and universities have realized the importance of practical teaching, there is still a lack of specific measures for different majors, and some school still put their work focus on scientific research and theoretical teaching, and did not put the college students' practical ability training in the core position. The practice in a lot of teaching plans of the school information management major is difficult to implement and practical teaching is often a mere formality. In addition, even developing practice teaching, often appear the phenomenon that experimental project design is not reasonable and scientific, leading to the practice teaching effect is not good enough. The workload to guide students to practice being big and very hard, the outdated workload assessment mechanism limits the enthusiasm of teachers to guide students to practice.

Practical Ability Training Target Is not Clear, so that the Students Do not Pay Attention to. Information management major is a profession to train informational talents, also to train of information resources development and management professionals. From the perspective of knowledge structure, information management major is at the intersection of management science, information science and technology and related fields, is a typical interdisciplinary subject, is a highly integrated management and technical expertise which is difficult to clear and definite the 
goal of professional practice ability training. In addition, assessment of practice teaching link is relatively difficult and mostly is a formality. Students are reluctant to spend too much time and effort to practice and even aren't aware of the importance of practice to improve their ability, even in are often perfunctory.

Teachers Themselves Lack of Practical Experience. Information management professional is a fast emerging professional, many teachers are coming transformation of other professional, and new teachers, although are information management professional doctoral, master's degree, with solid foundation of the professional theories, But they are generally insufficient of the actual experience of information management, after graduation directly into the university, aren't in enterprises and institutions to carry out the experience of the actual information management, after the work are busy in the daily teaching and scientific research, lack of necessary communication and communication with the business community, many teachers do not understand the reality of enterprise information management and demand. In addition, what main to see for teachers in the title evaluation are research projects, published papers, and the effectiveness of teaching practice and the interests of teachers is not related, which reduces the enthusiasm of teachers to improve the ability of practice teaching, many teachers are unwilling to spend more energy in practical teaching, which has become a major obstacle to the smooth development of professional practice teaching.

Separate From the Enterprise Practice and the Low Teaching Methods. In the process of enterprise actual informationization, due to differences in specific industries, all enterprises, business, personnel, finance, management, and other aspects of the actual situation, specific enterprise informatization project will have many aspects of the special requirements of the, but in teaching is difficult to enterprises with the actual needs of the application and the contact. Information management profession attaches great importance to the combination of theoretical knowledge and practical ability cultivation. However, the current teaching methods and ideas still take the traditional theory of indoctrination style of teaching methods as main method, Lacking of classroom interaction between teachers and students, lacking of real case analysis, lacking of task driven teaching, project driven teaching, etc. which is not conducive for students practical ability to reach the goal of professional training requirements of information management. On the teaching methods, lack of modern teaching means, even with the use of multimedia teaching, it is up to the blackboard, rarely in the room to carry out learning by doing, learning by doing and other teaching methods.

Have Challenges from Emerging Technology. Many emerging technologies and applications have penetrated into every aspect of the organization's operations and social life. A digital and intelligent and based on information / data management decisions and resource competition showed that the fusion of technology and management has reached a new level of development. New technology and applications, such as networking, mobile commerce, cloud computing, data, app and other and now the Internet changes in thinking, Internet + thinking philosophy and business behavior, share the development of economy of the new format, the fuse of professional practice skills and concepts proposed new challenges.

\section{Several Measures to Cultivate the Practical Ability of Information Management Major}

Do Well the Top Level Design of Training Program. No real reform of the talent training scheme, no class really change, no substantive change at classroom (experiment, training and practice), the school education and teaching reform will become a mere formality and the contents are empty, becoming superficial, the slogan of reform. By classifying knowledge and skills, can clearly tie up the curriculum content and structure of course system information management professional ability, according to the practical goal's requirements of information management professional, the practical ability training in teaching can be divided into two pieces of practice and social practice. (1)The link of practice teaching: includes curriculum experiment, curriculum design, professional 
practice, graduation design; (2) Social practice link: includes the cognitive system practice, graduation practice, information system development and practice of project management, information system operation and management practice, the practice of the information resource management and other extracurricular practice etc.. Do well curriculum design matched with major practice ability training objectives, as our school set up the "information system design and development" curriculum design, which requires each student to design an information system that has a certain practicality and quality requirements, "ERP platform training" course is a comprehensive practical skills courses, "information technology front and application" course closely followed by the latest development of information technology design courses.

Do a Good Job in the Construction of Laboratory and Practice Base. The construction of laboratory and practice base is directly related to the quality of practical teaching, and it has a very important role in the training of high quality talent. Build the necessary hardware and software resources of the laboratory, and do a good job in laboratory management, to ensure that all experimental projects are able to normally open, and to achieve good results of the experimental teaching. Students practical ability cannot be separated from the help of enterprises, through the cooperation between schools and enterprises, to form a mutually beneficial and win-win partnership and establish a stable practice base. Formulate practical teaching standards, establish of a number of high level of practical teaching core platform and collaborative education platform.

Do Good Construction of "Double Qualification" Teacher's Team. Training practical ability of the application of skilled personnel need to have an excellent application of Technical Teachers. The constraints of the current local colleges and universities especially in newly established undergraduate colleges training application technology talents bottleneck are teachers, increasing the efforts of introduction and cultivation of "double teacher type" teachers, let full-time teachers to the enterprise actual job for more than a year, and make the teachers not only have the generous professional knowledge, solid industry practical knowledge, but also have a strong professional ability, practice ability teaching, application research and development ability and the ability of social service, truly achieve the "double teacher type" and "double technical type", "double" level. Secondly, from the enterprise the staff is hired with a certain theoretical foundation and rich practical experience to do a full-time or part-time job, or bear part of a course or part of the contents of teaching, or guidance of participation in the part of practice teaching. Finally, to encourage teachers to participate in the emerging technology conference and training, to participate in the "double teacher" teacher certification, regularly send teachers to practice in enterprises such as a series of measures to enhance the level of the teachers' practice teaching. Finally, encourage teachers to participate in the emerging technology conference and training and to participate in the "double teacher" teacher certification, regularly send teachers to practice in enterprises such as a series of measures to enhance the level of the teachers' practice teaching.

Do Well in Practice Course Construction and Teaching Design. Be clear the position, function of each course, module or practice link in the whole course system in the whole professional course system, and so on. After having set up a good curriculum system, but also according to the practical ability training objectives and requirements, do a good job in course construction and teaching design, which needs to do well in complete the course content and the teaching design. If necessary, need self-compiled school-based curriculum. Course construction should strengthen the case and enrich the practice link, through the teaching case; it can be used for students to demonstrate the operation of the system, to lay the foundation for practice. Only each course can build a scientific ability system, so can truly build a scientific system of professional ability system, to form an applied technology ability system in Universities.

Reform the Teaching Mode. With a scientific and reasonable curriculum system, teaching content and teaching design, there must be a teaching mode to adapt to the implementation. The reform of curriculum system, teaching content and teaching methods must be carried out simultaneously. The information management profession can explore the implementation of action 
oriented teaching, using the integrated teaching mode of "teaching- learning- doing", making theory teaching and practice teaching organically linked together, so that students master the knowledge in practice, improve their quality in practice, in the practice ability training. Our school fuse professional mainly adopts the following reform models: take the task of driving, PBL teaching method etc., often organize the students to develop for small system of school department management function. Cooperated with local e-commerce enterprises, really go to the online shop operators to train students practical operation ability; Carry out the second classroom, listen to academic lectures, and participate in various disciplines contest and entrepreneurship competition, etc. Organize students to carry out research study project to improve the student's practice ability; Take the project driven approach, docking local business market, using of all opportunities to lead the development of higher level programming students to develop real practical management system.

Promote Construction of the Characteristic Major. For the construction of professional ability system, different schools, majors and different individuals can explore on the construction of different dimensions and evaluation criteria according to their different professional orientation, professional characteristics and professional objectives. Establishing the innovation and entrepreneurship education system, to achieve the combination of professional education and innovation and entrepreneurship education, establish teaching management and quality control system under the school enterprise cooperation and education mode. In addition, achieve the docking of professional and industrial, actively adapt to the transformation of economic development mode and the optimization and upgrading of industrial structure, also to explore the construction of "working process oriented curriculum system, explore curriculum and post docking, docking of teaching materials and skills, the docking of teaching process and the production process, behavior habit and professionalism docking graduation certificate and professional qualification certificate docking a series of docking target measures, Which comprehensively improve the level of professional construction and industrial service capabilities. According to the application technology of positioning and the social actual needs, in the four years of university training purpose, there are plans to gradually carried out experiments, curriculum design, training and practice, to improve the level of students' practical ability, formed distinctive fuse professional personnel training system model.

In a word, cultivation of students' practical ability, its focus is not to let the students grasp some simple skills, but to establish the process of the unity of practice in the explicit practical skills and implicit mental thinking ability integration based on the technical skills. In addition, in the practical ability especially in experimental ability training, should reduce the ratio of verification experiments, increase the design, comprehensive and innovative and open the proportion, in order to cultivate students professional design ability and ability of practice and innovation.

\section{Acknowledgements}

This research was financially supported by Hunan Province 2012 Regular Institutions of Higher Education Teaching Reform Project(Xiang Jiao Tong ([2012]401 - 438) - "A study on the Information management major practice teaching reform and innovation based on the double characteristics of locality and school", and supported by educational reform project of Xiangnan University (09Z001).

\section{References}

[1] Ministry of Education Teaching Guidance Committee of Management Science and Engineering Discipline, CNAIS: China information system curricula 2011[M], Tsinghua University Press, 2011. 
[2] Tao Wan: Methods for promotion practical ability of major of information management and information system in the application-oriented universities, J. Changchun Inst. Tech. (Soc. Sci. Edi), 2012, Vol. 13, No.2.

[3] Su Jing, Xiao Pan, Zhu Qiang: Construction of local application-oriented university and transformation of local undergraduate university, Henan Education, 2014, No.06.

[4] Dong Liping: The Transformation and Development of Local Colleges and Universities and the Establishment of Colleges and Universities of Applied Science, Education Research, 2014, No. 8 . 